InfoTekJar : Jurnal Nasional Informatika dan

Teknologi Jaringan

ISSN (Print) 2540-7597 | ISSN (Online) 2540-7600

\title{
Penerapan Algoritma One Time Pad \& Linear Congruential Generator Untuk Keamanan Pesan Teks
}

\author{
Rachmat Aulia ${ }^{1}$, Ahmad Zakir ${ }^{2}$, Muhammad Zulhafiz ${ }^{1}$ \\ ${ }^{1}$ Prodi Teknik Informatika Fakultas Teknik dan Komputer Universitas Harapan Medan, Jl.H.M Joni No.70C, Medan, Sumatera Utara, Indonesia \\ ${ }_{2}^{2}$ Prodi Sistem Informasi Fakultas Teknik dan Komputer Universitas Harapan Medan, Jl.H.M Joni No.70C, Medan, Sumatera Utara, Indonesia
}

\section{KEYWORDS}

Kriptografi, One Time Pad, Linier

Congruential Generator, OTP, LCG

\begin{tabular}{|c|}
\hline CORRESPONDENCE \\
\hline E-mail: jackm4t@gmail.com \\
\hline $\begin{array}{l}\text { suratzakir@gmail.com } \\
\underline{\text { muhammadzulhafiz021@gmail.com }}\end{array}$ \\
\hline
\end{tabular}

\section{PENDAHULUAN}

Perkembangan teknologi semakin hari semakin meningkat. Hal ini dapat menyebabkan semakin tingginya tingkat ancaman terhadap keamanan penyebaran data dan informasi. Keamanan merupakan masalah utama yang terdapat dalam jaringan global berkaitan dengan pengiriman informasi dari sumber menuju target begitupun sebaliknya [1]. Tidak ada yang dapat memastikan pesan yang dikirim melalui jaringan internet dalam kondisi aman. Seperti yang kita ketahui, saat ini internet sangat mudah untuk diperoleh, sehingga membuka peluang atau celah bagi orang-orang yang tidak bertanggung jawab dalam mencuri informasi dan data-data pribadi yang dimiliki perusahaan maupun individual. Data atau informasi yang menjadi target pencurian adalah berkas-berkas atau dokumen digital yang mempunyai nilai tinggi (valuable).

Keamanan informasi merupakan prioritas utama di era saat ini. Dokumen-dokumen ataupun catatan-catatan kecil namun penting dapat menyebabkan kerugian yang cukup besar jika tidak diberikan keamanan tambahan. Untuk mengatasi itu dibutuhkan mekanisme keamanan digital yang tergolong ke dalam bidang kriptografi. Kriptografi (cryptography) awalnya https://doi.org/10.30743/infotekjar.v4i1.1590

\begin{abstract}
A $\quad$ B $\mathbf{S}$ T $\mathbf{R}$ A $\mathbf{C}$ T
Keamanan informasi memiliki peran penting dalam teknologi informasi. Pengiriman pesan ada baiknya dilakukan dengan menerapkan teknik kriptografi. Hal ini dilakukan untuk pendayapan pesan. Kriptografi dapat diartikan sebagai pesan berbentuk teks, yang tidak tidak beraturan, dimana ketika sampai dengan pasti ke target, pesannya dapat dikembalikan lagi ke bentuk aslinya. Kriptografi diklasifikasikan dalam tiga: simetri, asimetri, dan hash. One Time Pad merupakan jenis kriptografi simetris dimana enkripsi dan dekripsinya ang berbeda. Proses pada One time Pad adalah panjang pesan harus sama dengan panjang kunci. Salah satu mekanisme yang dapat membantu dalam membangkitkan kunci pada algoritma One Time Pad adalah menggunakan pembangkit kunci yang mampu Pembangkit kunci tersebut adalah Linier Congruential Generator. pembangkit bilangan acak tertua dan cukup terkenal. Kombinasi dari kedua teknik ini yaitu OTP dan LCG dapat menghasilkan enkripsi dan deskripsi pesan secara efisien, sehingga pesan aman pada saat dikirim melalui internet.
\end{abstract}

diadopsi dari bahasa yunani yang memiliki dua suku kata: kryptos (tersembunyi) dan graphein (tulisan), jadi apabila digabungkan menjadi "tulisan tersembunyi" [2]. Kriptografi tidak hanya mencakup teknik-teknik menyandikan informasi, tetapi juga teknik untuk membongkar sandi. Terdapat dua proses utama dalam kriptografi: enkripsi dan dekripsi. Enkripsi adalah teknik yang mengubah plaintext menjadi ciphertext. Sedangkan deskripsi sebaliknya.

Kriptografi mempunyai variasi teknik dan metode, salah satunya adalah metode On Time Pad (OTP). On Time Pad adalah teknik enkripsi yang menggunakan pasangan plaintext dengan sebuah kunci rahasia yang diperoleh secara acak. Kemudian setiap bit dari plaintext dienkripsi dengan mengkombinasikan dengan bit tambahan yang diperoleh dari kunci acak menggunakan penjumlahan modulo. Keamanan dari One Time Pad sendiri bergantung pada kunci acak yang digunakan. Semakin tinggi jumlah kunci acak yang digunakan dan tidak menggunakannya kembali, maka keamanan chipertext dari One Time Pad akan semakin tinggi.

Penerapan kunci acak pada One Time Pad haruslah dapat digunakan kembali ketika ingin melakukan teknik dekripsi. Oleh karena itu diperlukan suatu pembangkit bilangan acak yang 
dapat digunakan kembali, salah satunya adalah metode Linier Congruential. Linear Congruential Method (LCM) adalah bilangan yang tidak dapat diprediksi kemunculannya. Tidak ada komputasi yang benar-benar menghasilkan deret bilangan acak secara sempurna [3]. LCM merupakan metode pembangkit bilangan acak semu yang menghasilkan bilangan acak yang memiliki periode dan sangat ditentukan oleh parameter input sehingga bilangan yang dibangkitkan tidak sepenuhnya acak.

\section{METODE}

\section{Kriptografi}

Untuk mengubah pesan asli ke dalam bentuk yang tidak beraturan diperlukan suatu tahapan. Dalam ilmu kriptografi, tahapan untuk menghasilkan pesan yang terenkripsi dapat diterapkan sesuai ilustrasi berikut:

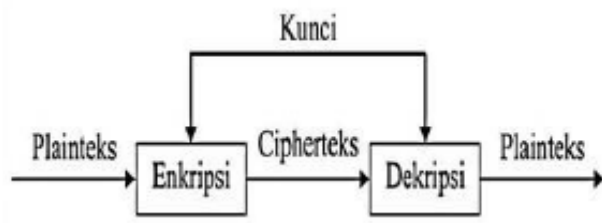

Gambar 1. Dasar Kriptografi [4]

Teknik enkripsi dapat dijalankan dengan memasukkan pesan asli dan kunci, selanjutnya menghasilkan luaran ciphertext (pesan terenkripsi). Ciphertext dapat dikembalikan dalam bentuk aslinya (plaintext) dengan memasukkan kembali kunci berserta ciphertext-nya.

\section{One Time Pad (OTP)}

Algoritma OTP mempunyai panjang kunci yang sama dengan panjang plaintext, sehingga tidak ada kebutuhan untuk mengulang penggunaaan kunci selama proses enkripsi. Adapun aturan enkripsi dan dekripsi dari one time pad adalah sebagai berikut:

1. Enkripsi $C=(\mathrm{Pi}+\mathrm{Ki}) \bmod 26$

2. Dekripsi $\mathrm{C}=(\mathrm{Pi}-\mathrm{Ki}) \bmod 26$

Note: $\mathrm{P}_{\mathrm{i}}$ adalah plaintext

$\mathrm{K}_{\mathrm{i}}$ adalah kunci.

Contoh: Bila diketahui Plainteks: "WANGIJERUK" dengan kunci: "RKBIRKBIRK". Jika kita asumsikan $\mathrm{A}=0, \mathrm{~B}=1, \ldots \ldots$, $\mathrm{Z}=25$, dengan menggunakan rumus enkripsi $\Rightarrow$ " $C=(\mathrm{Pi}+\mathrm{Ki})$ mod 26", maka diperolehlah hasil ciphertext "NKOOZTFZKU" yang didapat dari perhitung sebagai berikut:

Tabel 1. Contoh Proses Enkripsi

\begin{tabular}{|l|l|l|l|}
\hline \multicolumn{1}{|c|}{ Rumus } & \multicolumn{1}{|c|}{ Nilai } & \multicolumn{1}{c|}{ Hasil } & Char \\
\hline$(\mathrm{W}+\mathrm{R}) \bmod 26$ & $=(22+17) \bmod 26=$ & 13 & $\mathrm{~N}$ \\
\hline$(\mathrm{A}+\mathrm{K}) \bmod 26$ & $=(0+10) \bmod 26=$ & 10 & $\mathrm{~K}$ \\
\hline$(\mathrm{N}+\mathrm{B}) \bmod 26$ & $=(13+1) \bmod 26=$ & 14 & $\mathrm{O}$ \\
\hline$(\mathrm{G}+\mathrm{I}) \bmod 26$ & $=(6+8) \bmod 26=$ & 14 & $\mathrm{O}$ \\
\hline$(\mathrm{I}+\mathrm{R}) \bmod 26$ & $=(8+17) \bmod 26=$ & 25 & $\mathrm{Z}$ \\
\hline$(\mathrm{J}+\mathrm{K}) \bmod 26$ & $=(9+10) \bmod 26=$ & 19 & $\mathrm{~T}$ \\
\hline$(\mathrm{E}+\mathrm{B}) \bmod 26$ & $=(4+1) \bmod 26=$ & 5 & $\mathrm{~F}$ \\
\hline$(\mathrm{R}+\mathrm{I}) \bmod 26$ & $=(17+8) \bmod 26=$ & 25 & $\mathrm{Z}$ \\
\hline$(\mathrm{U}+\mathrm{R}) \bmod 26$ & $=(20+17) \bmod 26=$ & 11 & $\mathrm{~K}$ \\
\hline$(\mathrm{K}+\mathrm{I}) \bmod 26$ & $=(10+10) \bmod 26=$ & 20 & $\mathrm{U}$ \\
\hline
\end{tabular}

Kemudian untuk mendekripsikannya lakukan lagi perhitungan diatas dengan menggunakan " $\mathrm{Pi}=(\mathrm{Ci}-\mathrm{Ki})$ mod 26", dengan menggunakan hasil chipertext dari Enkripsi $\Rightarrow$ "NKOOZTFZKU" dan kunci = "RKBIRKBIRK", maka dapatlah hasil dari proses dekripsi = "WANGIJERUK" [5]
Tabel 2. Contoh Proses Dekripsi

\begin{tabular}{|c|c|c|c|}
\hline Rumus & Nilai & Hasil & Char \\
\hline$(\mathrm{N}-\mathrm{R}) \bmod 26$ & $=(13-17) \bmod 26=$ & 22 & $\mathrm{~W}$ \\
\hline$(\mathrm{K}-\mathrm{K}) \bmod 26$ & $=(10-10) \bmod 26=$ & 0 & $\mathrm{~A}$ \\
\hline$(\mathrm{O}-\mathrm{B}) \bmod 26$ & $=(14-1) \bmod 26=$ & 13 & $\mathrm{~N}$ \\
\hline$(\mathrm{O}-\mathrm{I}) \bmod 26$ & $=(14-8) \bmod 26=$ & 6 & $\mathrm{G}$ \\
\hline$(\mathrm{Z}-\mathrm{R}) \bmod 26$ & $=(25-17) \bmod 26=$ & 8 & $\mathrm{I}$ \\
\hline$(\mathrm{T}-\mathrm{K}) \bmod 26$ & $=(19-10) \bmod 26=$ & 9 & $\mathrm{~J}$ \\
\hline$(\mathrm{F}-\mathrm{B}) \bmod 26$ & $=(5-1) \bmod 26=$ & 4 & $\mathrm{E}$ \\
\hline$(\mathrm{Z}-\mathrm{I}) \bmod 26$ & $=(25-8) \bmod 26=$ & 17 & $\mathrm{R}$ \\
\hline$(\mathrm{K}-\mathrm{R}) \bmod 26$ & $=(11-17) \bmod 26=$ & 20 & $\mathrm{U}$ \\
\hline$(\mathrm{U}-\mathrm{I}) \bmod 26$ & $=(20-10) \bmod 26=$ & 10 & $\mathrm{~K}$ \\
\hline
\end{tabular}

Note : Penjabaran pengurangan baris ke-1 (tabel 2$) \Rightarrow((\mathrm{N}-\mathrm{R})$ $\bmod 26)=(13-17=(-4))$, jika minus maka hasil pengurangan ditambah dengan nilai mod agar dekripsinya berhasil, (4) $+26=22$.

\section{Linier Congruential Generator (LCG)}

Bilangan acak adalah bilangan yang tidak dapat diprediksi kemunculannya. Tidak ada komputasi yang benar-benar menghasilkan deret bilangan acak secara sempurna. Banyak algoritma atau metode yang dapat digunakan untuk membangkitkan bilangan acak salah satunya adalah pembangkit bilangan acak Linear Congruential Generators [3]. LCG adalah algoritma yang sering diimplementasikan pada beberapa bahasa pemrograman untuk membangkitkan bilangan acak. LCG didefinisikan dalam relasi rekurens:

$$
X_{n}=\left(a X_{n}-\mathrm{i}+\mathrm{b}\right) \bmod m
$$

Contoh:

Diketahui $=>\mathrm{a}=5, \mathrm{~b}=3, \mathrm{~m}=26, \& X_{n} \mathrm{i}=8$

Untuk mengetahui hasilnya dapat dilihat seperti berikut:

Tabel 3. Contoh Proses Pembangkit Kunci

\begin{tabular}{|l|l|l|l|}
\hline \multicolumn{1}{|c|}{ Rumus } & \multicolumn{1}{|c|}{ Nilai } & Hasil & Char \\
\hline$\left(a X_{n} \mathrm{i}+\mathrm{b}\right) \bmod m$ & $=(5.8+3) \bmod 26=$ & 17 & $\mathrm{R}$ \\
\hline$\left(a X_{n} \mathrm{i}+\mathrm{b}\right) \bmod m$ & $=(5.17+3) \bmod 26=$ & 10 & $\mathrm{~K}$ \\
\hline$\left(a X_{n} \mathrm{i}+\mathrm{b}\right) \bmod m$ & $=(5.10+3) \bmod 26=$ & 1 & $\mathrm{~B}$ \\
\hline$\left(a X_{n} \mathrm{i}+\mathrm{b}\right) \bmod m$ & $=(5.1+3) \bmod 26=$ & 8 & $\mathrm{I}$ \\
\hline$\left(a X_{n} \cdot \mathrm{i}+\mathrm{b}\right) \bmod m$ & $=(5.8+3) \bmod 26=$ & 17 & $\mathrm{R}$ \\
\hline$\left(a X_{n} \mathrm{i}+\mathrm{b}\right) \bmod m$ & $=(5.17+3) \bmod 26=$ & 10 & $\mathrm{~K}$ \\
\hline$\left(a X_{n} \mathrm{i}+\mathrm{b}\right) \bmod m$ & $=(5.10+3) \bmod 26=$ & 1 & $\mathrm{~B}$ \\
\hline$\left(a X_{n} \cdot \mathrm{i}+\mathrm{b}\right) \bmod m$ & $=(5.1+3) \bmod 26=$ & 8 & $\mathrm{I}$ \\
\hline$\left(a X_{n} \mathrm{i}+\mathrm{b}\right) \bmod m$ & $=(5.8+3) \bmod 26=$ & 17 & $\mathrm{R}$ \\
\hline$\left(a X_{n} \mathrm{i}+\mathrm{b}\right) \bmod m$ & $=(5.17+3) \bmod 26=$ & 10 & $\mathrm{~K}$ \\
\hline
\end{tabular}

$X_{n}=$ bilangan acak ke-n dari deretnya $X_{n-1}=$ bilangan acak sebelumnya $a=$ factor pengali $b=$ penambah (increment) $m=$ modulus (a , b , dan m semuanya konstans).

Kunci pembangki adalah $\mathrm{X}_{0}$ yang disebut seed (secret seed). Dalam hal ini $\mathrm{X}_{0}$ bersifat rahasia. LCG mempunyai periode tidak lebih besar dari m, dan pada kebanyakan kasus periodenya kurang dari itu. Periode penuh (m-1) kepunyaan LCG dapat terjadi jika memenuhi syarat sebagai berikut: [6]

1. b relative prima terhadap $m$

2. a-1 dapat dibagi dengan semua faktor prima dari $m$

3. a-1 adalah kelipatan 4 jika $m$ adalah kelipatan 4

4. $\mathrm{m}>$ maks $\left(\mathrm{a}, \mathrm{b}, \mathrm{X}_{0}\right)$

5. $a>0, b>0$

\section{Analisis Algoritma}

Analisis merupakan aktivitas yang terjadi untuk menjelaskan langkah-langkah berkaitan dengan enkripsi dan dekripsi menggunakan algoritma One Time Pad dan penerapan metode Linier Congruential Generator untuk membangkitkan suatu kunci. Bagian ini terdiri dari key generator, enkripsi dan dekripsi. 


\section{Key Generator}

Analisis pembangkitan kunci pada One Time Pad menggunakan nilai indeks karakter yang dioperasikan dengan kunci dan modulus dari jumlah karakter yang digunakan. Pesan Teks yang akan dienkripsi menggunakan karakter huruf besar, huruf kecil, angka, dan tanda baca yang dapat dilihat pada tabel berikut:

Tabel 4. Daftar Karakter Enkripsi \& Deskripsi [6]

\begin{tabular}{|c|c|c|c|}
\hline Karakter & Kode & Karakter & Kode \\
\hline Space & 0 & $\mathrm{P}$ & 48 \\
\hline$!$ & 1 & $\mathrm{Q}$ & 49 \\
\hline " & 2 & $\mathrm{R}$ & 50 \\
\hline \# & 3 & $S$ & 51 \\
\hline$\$$ & 4 & $\mathrm{~T}$ & 52 \\
\hline$\%$ & 5 & $\mathrm{U}$ & 53 \\
\hline$\&$ & 6 & $\mathrm{~V}$ & 54 \\
\hline ' & 7 & W & 55 \\
\hline ( & 8 & $X$ & 56 \\
\hline$)$ & 9 & $\mathrm{Y}$ & 57 \\
\hline * & 10 & $\mathrm{Z}$ & 58 \\
\hline+ & 11 & [ & 59 \\
\hline , & 12 & 1 & 60 \\
\hline- & 13 & ] & 61 \\
\hline . & 14 & $\wedge$ & 62 \\
\hline 1 & 15 & - & 63 \\
\hline 0 & 16 & - & 64 \\
\hline 1 & 17 & $\mathrm{a}$ & 65 \\
\hline 2 & 18 & $\mathrm{~b}$ & 66 \\
\hline 3 & 19 & $\mathrm{c}$ & 67 \\
\hline 4 & 20 & $\mathrm{~d}$ & 68 \\
\hline 5 & 21 & $\mathrm{e}$ & 69 \\
\hline 6 & 22 & $\mathrm{f}$ & 70 \\
\hline 7 & 23 & $\mathrm{~g}$ & 71 \\
\hline 8 & 24 & $\mathrm{~h}$ & 72 \\
\hline 9 & 25 & $\mathrm{i}$ & 73 \\
\hline : & 26 & $j$ & 74 \\
\hline ; & 27 & $\mathrm{k}$ & 75 \\
\hline$<$ & 28 & 1 & 76 \\
\hline$=$ & 29 & $\mathrm{~m}$ & 77 \\
\hline$>$ & 30 & $\mathrm{n}$ & 78 \\
\hline$?$ & 31 & o & 79 \\
\hline @ & 32 & $p$ & 80 \\
\hline $\mathrm{A}$ & 33 & $\mathrm{q}$ & 81 \\
\hline B & 34 & $\mathrm{r}$ & 82 \\
\hline $\mathrm{C}$ & 35 & $\mathrm{~s}$ & 83 \\
\hline $\mathrm{D}$ & 36 & $\mathrm{t}$ & 84 \\
\hline E & 37 & $\mathrm{u}$ & 85 \\
\hline $\mathrm{F}$ & 38 & $\mathrm{~V}$ & 86 \\
\hline G & 39 & $\mathrm{w}$ & 87 \\
\hline $\mathrm{H}$ & 40 & $\mathrm{x}$ & 88 \\
\hline I & 41 & $\mathrm{y}$ & 89 \\
\hline $\mathrm{J}$ & 42 & $\mathrm{z}$ & 90 \\
\hline $\mathrm{K}$ & 43 & \{ & 91 \\
\hline $\mathrm{L}$ & 44 & 1 & 92 \\
\hline M & 45 & \} & 93 \\
\hline $\mathrm{N}$ & 46 & $\sim$ & 94 \\
\hline $\mathrm{O}$ & 47 & & \\
\hline
\end{tabular}

Berikutnya, proses pembangkitan kunci OTP menggunakan LCG, dapat dilakukan dengan cara menyepakati parameter yang digunakan untuk mengirim dan menerima pesan teks. Contoh pesan yang akan dikirimkan adalah "Saya Rachmat".

Nilai parameter M (modulus) yang digunakan adalah 95. Karena berdasarkan tabel 4 di atas, kode dimulai dari nilai nol (0).

Berikut adalah nilai-nilai awal parameter yang digunakan untuk menghasilkan nilai LCG-nya:

Formula $=>X \_n=\left(a X \_(n-1)+b\right) \bmod M$, dimana

$\mathrm{X}_{0}=34$

$\mathrm{a}=12$ $\mathrm{b}=22$

Proses nilai $L C G$ untuk $X_{1}$ :

$\mathrm{X} \_\mathrm{n}=1=(12 * 34)+22 \bmod 95$

Hasilnya adalah 50

Selanjutnya, lakukan proses nilai LCG-nya s.d 18 kali proses, yang hasil keseluruhannya seperti berikut:

Tabel 5. Nilai Acak LCG

\begin{tabular}{|c|c|}
\hline $\mathrm{X}(\mathrm{i})$ & $\mathrm{LCG}(\mathrm{i})$ \\
\hline 1 & 50 \\
\hline 2 & 52 \\
\hline 3 & 76 \\
\hline 4 & 79 \\
\hline 5 & 20 \\
\hline 6 & 72 \\
\hline 7 & 31 \\
\hline 8 & 14 \\
\hline 9 & 0 \\
\hline
\end{tabular}

\begin{tabular}{|c|c|}
\hline $\mathrm{X}(\mathrm{i})$ & $\mathrm{LCG}(\mathrm{i})$ \\
\hline 10 & 22 \\
\hline 11 & 1 \\
\hline 12 & 34 \\
\hline 13 & 50 \\
\hline 14 & 52 \\
\hline 15 & 76 \\
\hline 16 & 79 \\
\hline 17 & 20 \\
\hline 18 & 72 \\
\hline
\end{tabular}

\section{Enkripsi}

Kegiatan yang mentransformasikan pesan asli menjadi pesan acak (tidak beraturan) sehingga pesan tidak dimengerti atau dipahami maknanya [8]. Metode OTP mengenkripsi pesan menggunakan key generator yang terdapat pada metode LCG yang telah dijabarkan sebelumnya. Adapun plaintext yang digunakan pada proses enkripsi adalah "Saya Rachmat".

Tahapan enkripsi selangkapnya dijelaskan sebagai berikut:

1. Konversikan pesan teks yang akan diubah ke nilai karakter, seperti tampilan berikut:

Tabel 6. Konversi Plaintext ke Nilai Karakter

\begin{tabular}{|l|l|l|l|c|l|l|l|l|l|}
\hline S & $\mathbf{a}$ & $\mathbf{y}$ & $\mathbf{a}$ & (spasi) & $\mathbf{R}$ & $\mathbf{a}$ & $\mathbf{c}$ & $\mathbf{h}$ & $\mathbf{m}$ \\
\hline 51 & 65 & 89 & 65 & 0 & 50 & 65 & 67 & 72 & 77 \\
\hline $\mathbf{a}$ & $\mathbf{t}$ & & & & & & & & \\
\hline 65 & 84 & & & & & & & & \\
\hline
\end{tabular}

2. Enkripsikan pesan teks menggunakan hasil dari nilai acak yang berasal dari metode LCG

Formula $\Rightarrow \mathrm{C}=(\mathrm{Pi}+\mathrm{Ki}) \bmod 95$

Karena plaintext ("Saya Rachmat") yang akan dienkripsi berjumlah dua belas (12) karakter, maka nilai acak LCG yang digunakan cukup sampai dua belas juga

Tabel 7. Enkripsi Plaintext

\begin{tabular}{|c|c|}
\hline X(i) & LCG(i) \\
\hline 1 & 6 \\
\hline 2 & 22 \\
\hline 3 & 70 \\
\hline 4 & 49 \\
\hline 5 & 20 \\
\hline 6 & 27 \\
\hline
\end{tabular}

\begin{tabular}{|c|c|}
\hline X(i) & LCG(i) \\
\hline 7 & 1 \\
\hline 8 & 81 \\
\hline 9 & 72 \\
\hline 10 & 4 \\
\hline 11 & 66 \\
\hline 12 & 23 \\
\hline
\end{tabular}

3. Konversi nilai enkripsi plaintext menjadi karakter ciphertext

Tabel 8. Konversi Nilai Enkripsi Plaintext ke Ciphertext

\begin{tabular}{|c|c|c|c|c|c|c|c|c|c|}
\hline 6 & 22 & 70 & 49 & 20 & 27 & $\mathbf{1}$ & $\mathbf{8 1}$ & $\mathbf{7 2}$ & $\mathbf{4}$ \\
\hline \& & 6 & f & Q & 4 & $;$ & $!$ & q & h & $\$$ \\
\hline 66 & 23 & & & & & & & & \\
\hline b & 7 & & & & & & & & \\
\hline
\end{tabular}

Hasil ciphertext-nya adalah:

\& $6 \mathrm{fQ} 4 ; ! \mathrm{qh} \$ \mathrm{~b} 7$

\section{Dekripsi}


Teknik yang mengembalikan ciphertext ke dalam bentuk aslinya (plaintext) [9]. Algoritma OTP menggunakan key generator yang dihasilkan dari metode LCG untuk melakukan proses dekripsi. Kunci yang digunakan adalah kunci yang dihasilkan pada saat mengerjakan proses enkripsi.

Tahapan dekripsi selangkapnya dijelaskan sebagai berikut:

1. Kembalikan karakter ciphertext ke dalam nilai hasil enkripsi plaintext

Tabel 9. Ubah Ciphertext Menjadi Nilai Enkripsi Plaintext

\begin{tabular}{|c|c|c|c|c|c|c|c|c|c|}
\hline \& & $\mathbf{6}$ & f & Q & 4 & $;$ & ! & q & h & \$ \\
\hline 6 & 22 & 70 & 49 & 20 & 27 & 1 & 81 & 72 & 4 \\
\hline b & 7 & & & & & & & & \\
\hline 66 & 23 & & & & & & & & \\
\hline
\end{tabular}

2. Lakukan proses dekripsi menggunakan nilai acak yang berasal dari metode $\mathrm{LCG}$

Formula $=>\mathrm{P}=(\mathrm{Ci}-\mathrm{Ki}) \bmod 95$

Tabel 10. Dekripsi Ciphertext

\begin{tabular}{|c|c|c|c|}
\hline $\mathrm{P}(\mathrm{i})$ & $\mathrm{Ci}$ & $\mathrm{Ki}$ & $(\mathrm{Ci}-\mathrm{Ki}) \bmod 95$ \\
\hline 1 & 6 & 50 & 51 \\
\hline 2 & 22 & 52 & 65 \\
\hline 3 & 70 & 76 & 89 \\
\hline 4 & 49 & 79 & 65 \\
\hline 5 & 20 & 20 & 0 \\
\hline 6 & 27 & 72 & 50 \\
\hline 7 & 1 & 31 & 65 \\
\hline 8 & 81 & 14 & 67 \\
\hline 9 & 72 & 0 & 72 \\
\hline 10 & 4 & 22 & 77 \\
\hline 11 & 66 & 1 & 65 \\
\hline 12 & 23 & 34 & 84 \\
\hline
\end{tabular}

3. Konversikan nilai hasil dekripsi ke plaintext

Tabel 11. Konversi Hasil Dekripsi ke Plaintext

\begin{tabular}{|c|c|c|c|c|c|c|c|c|c|}
\hline 51 & 65 & $\mathbf{8 9}$ & $\mathbf{6 5}$ & $\mathbf{0}$ & $\mathbf{5 0}$ & $\mathbf{6 5}$ & $\mathbf{6 7}$ & $\mathbf{7 2}$ & $\mathbf{7 7}$ \\
\hline S & a & y & a & space & R & a & c & h & m \\
\hline 65 & 84 & & & & & & & & \\
\hline a & t & & & & & & & & \\
\hline
\end{tabular}

\section{Kesimpulan}

Pengujian algoritma On Time Pad dan Linier Congruential Generator untuk mengamankan pesan teks, tidak hanya dilakukan pada contoh kasus yang telah dijabarkan di atas. Namun, percobaan telah dilakukan pada beberapan plaintext dengan pembangkit kunci yang berbeda juga, seperti yang tampak pada tampilan berikut:

\section{Tabel 12. Plaintext testing}

\begin{tabular}{|l|l|l|}
\hline No & \multicolumn{1}{|c|}{ Pesan Teks } & LCG \\
\hline 1 & $\begin{array}{l}17 \text { Agutus 11945 adalah hari keerdekaan } \\
\text { indonesia, dimana para pejuang dan pahlawan } \\
\text { dulu merebut dan mempertahankan indonesia dari } \\
\text { para penjajah yang ingin menguasai indosenia }\end{array}$ & 1945 \\
\hline 2 & $\begin{array}{l}\text { gempa di aceh pukul 07.35, telah memakan } \\
\text { korban sebanyak 35 orang }\end{array}$ & 60 \\
\hline 3 & $\begin{array}{l}\text { Insiden yang terjadi di Masjid Al Aqsa, Palestina } \\
\text { pada Jumat 21 Juli 2017 telah menimbulkan } \\
\text { keprihatinan banyak pihak, tak terkecuali }\end{array}$ & 189 \\
\hline
\end{tabular}

40 Rachmat Aulia

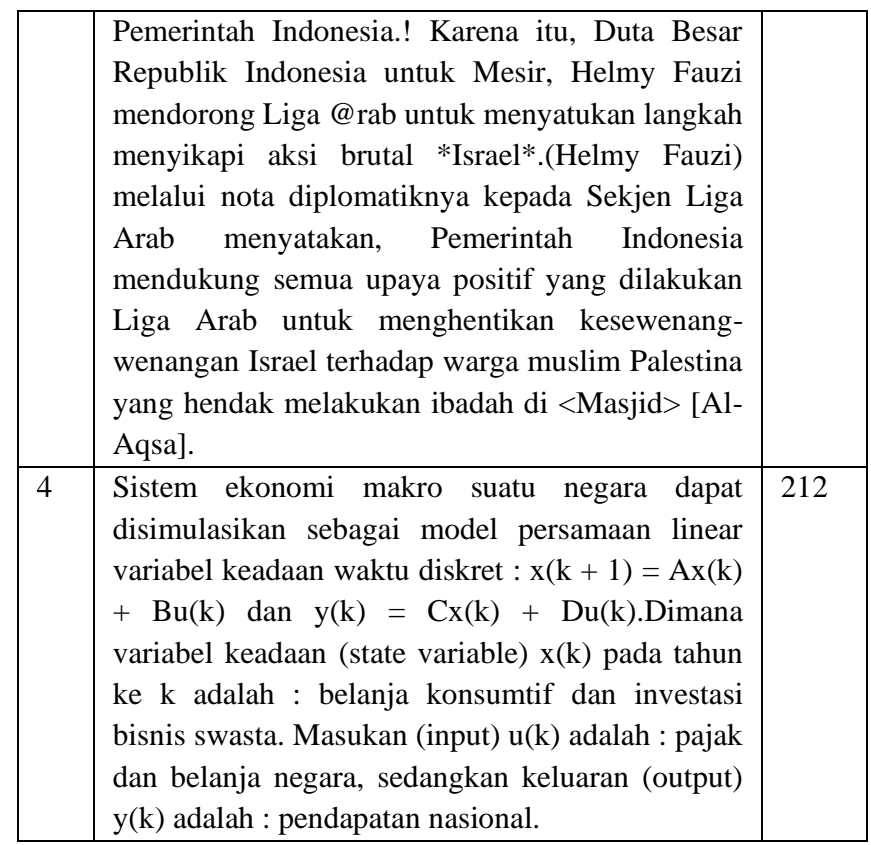

Tabel 13. Hasil Enkripsi Plaintext Testing

\begin{tabular}{|c|c|c|}
\hline No & \multicolumn{2}{|l|}{ Ciphertext } \\
\hline 1 & 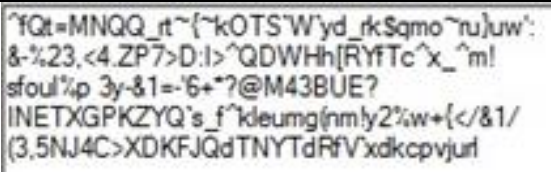 & \\
\hline 2 & 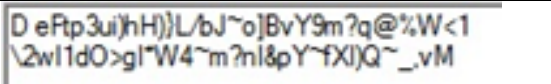 & \\
\hline 3 & 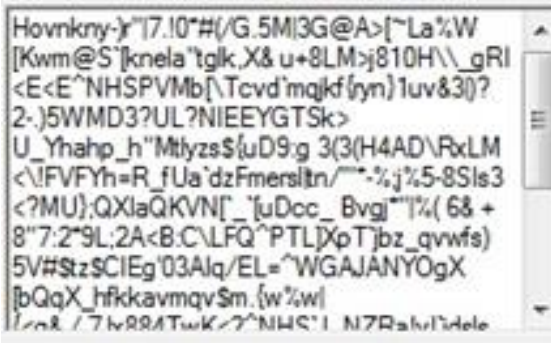 & 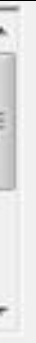 \\
\hline 4 & 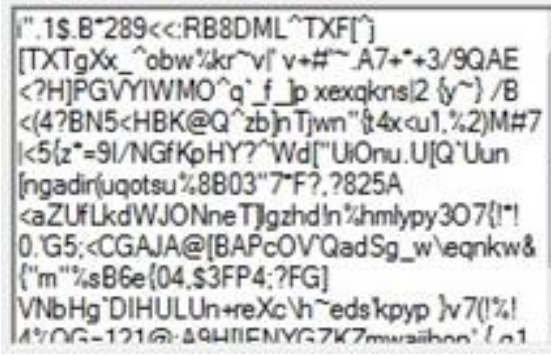 & E \\
\hline
\end{tabular}

Berdasarkan hasil pengujian plaintext di atas, didapatlah beberapa informasi:

1. Tingkat keamanan pesan dapat dikatakan cukup karena menggunakan dua metode: pertama, mengenkripsi pesan teksnya, dan kedua, menghasilkan pembangkit kunci enkripsinya untuk mengamankan pesan teks sebelum dikirim ke target.

2. Pesan yang telah terenkripsi tidak dapat dikembalikan ke dalam bentuk aslinya, jika pembangkit kuncinya salah atau tidak tepat.

3. Proses enkripsi mengkonsumsi waktu yang lama, jika pesan yang dimasukkan mengkonsumsi memori lebih dari 7.5 KB. 
4. Proses enkripsi berjalan lumayan lama, jika spesifikasi komputer yang digunakan prosesornya dibawah core I dan RAM-nya kecil.

5. Karakter teks yang digunakan tidak seperti yang terdapat dalam keyboard, namun dapat dikatakan cukup banyak karena melibatkan karakter "A - Z" (besar dan kecil), interger (0-9) dan beberapa karakter tertentu seperti yang tampak pada tabel 4 di atas.

6. Penerapan kedua metode ini OTP dan LCG untuk keamanan pesan teks hanya sebatas desktop saja. Kedepannya diharapan kedua metode ini, dapat diterapkan pada mobile dan web.

\section{REFERENCES}

[1] R. Aulia, "Pemanfaatan Website Sebagai Sarana Managing Data Dalam Suatu Organisasi (Studi Kasus: Pertemuan Ilmiah Nasional (Pin) Perhimpunan Dokter Spesialis Saraf Indonesia (Perdossi) 2013 Medan)," InfoTekJar (Jurnal Nasional Informatika dan Teknologi Jaringan), vol. 1, no. 1, pp. 1-6, 2016.

[2] S. Sitinjak, Y. Fauziah, and Juwairiah, "C-78 Aplikasi Kriptografi File Menggunakan Algoritma Blowfish," SemnasIF (Seminar Nasional Informatika), UPN "Veteran" Yogyakarta, 2010.

[3] M. Manssen, M. Weigel, and A. K. Hartmann, "Random number generators for massively parallel simulations on GPU," Eur. Phys. J. Spec. Top., vol. 210, no. 1, pp. 53-71, 2012.

[4] R. Aulia, A. Zakir, and D. A. Purwanto, "Penerapan Kombinasi Algoritma Base64 Dan Rot47 Untuk Enkripsi Database Pasien Rumah Sakit Jiwa Prof. Dr. Muhammad Ildrem," InfoTekJar (Jurnal Nasional Informatika dan Teknologi Jaringan), vol. 2, no. 2, pp. 146-151, 2018.

[5] M. Stamp, Information Security Principles and Practice, 2nd ed. Canada: Wiley, 2011.

[6] M. K. Harahap and R. Rina, "Kombinasi Kriptografi RSA dengan Linear Congruential Generator," SinkrOn (Jurnal \& Penelitian Teknik Informatika), vol. 3, no. 1, p. 267, 2018.

[7] "Ascii Table and Description." [Online]. Available: http://www.asciitable.com/. [Accessed: 10-Aug-2019].

[8] R. Aulia, A. Sembiring, A. Zakir, and B. A. U. Siregar, "PENYANDIAN TEXTS CHAT VIA INTERNET DENGAN ALGORITMA VIGENERE CIPHER," JSIK (Jurnal Sistem Informasi Kaputama), vol. 3, no. 2, pp. 2834, 2019.

[9] I. Gunawan, "Kombinasi Algoritma Caesar Cipher dan Algoritma RSA untuk pengamanan File Dokumen dan Pesan Teks," InfoTekJar (Jurnal Nasional Informatika dan Teknologi Jaringan), vol. 2, no. 2, pp. 124-129, 2018. 